\title{
A multi-group approach to examining language development in at-risk learners
}

\author{
A. DELCENSERIE ${ }^{1,3 *}$, F. GENESEE ${ }^{2}$, N. TRUDEAU ${ }^{3}$, and F. CHAMPOUX ${ }^{3}$ \\ ${ }^{1}$ Université de Montréal, Department of Psychology, ${ }^{2} \mathrm{McGill}$ University, Department of Psychology, and \\ ${ }^{3}$ Université de Montréal, École d'orthophonie et d'audiologie \\ ${ }^{*}$ Corresponding author: Audrey Delcenserie, Département de psychologie, Université de Montréal, Pavillon \\ Marie-Victorin, C.P. 6128, succursale Centre-Ville, Montréal (Québec), Canada, H3C 3J7. E-mail: audrey. \\ delcenserie@umontreal.ca
}

(Received 15 November 2017; revised 23 April 2018; accepted 18 July 2018;

first published online 17 September 2018)

\begin{abstract}
A battery of standardized language tests and control measures was administered to three groups of at-risk language learners - internationally adopted children, deaf children with cochlear implants, and children with specific language impairment - and to groups of second-language learners and typically developing monolingual children. All children were acquiring French, were matched on age, gender, and socioeconomic status, and were between age 5;0 and 7;3 at the time of testing. Differences between the at-risk and not-at-risk groups were evident in all domains of language testing. The children with SLI or CIs scored significantly lower than the IA children and all three at-risk groups scored lower than the monolingual group; the L2 and IA groups scored similarly. The results suggest that children with limited access to, or ability to process, early language input are at greater risk than children with delayed input to an additional language but otherwise typical or relatively typical early input.
\end{abstract}

Keywords: at-risk language acquisition; international adoption; cochlear implants; specific language impairment; second-language learning

Despite the universality of language learning, there are extensive individual differences in child language learning outcomes (Paradis, 2011; Szagun, 2004). To better understand language learning in depth, it is important to identify and understand the ways in which language acquisition can be vulnerable and robust under diverse conditions of development. In recent years, child language acquisition researchers have been interested in such variation and have sought to document and explain it by looking at children who are at-risk for language difficulties for various reasons, including children with specific language impairment (SLI) or children born deaf to hearing parents. An increasing number of theoretical reviews have called for multi-group comparisons of language outcomes that include at-risk groups, as well as common assessment instruments. For example, in a special issue on specific language impairment, Rice (2016) suggested that multi-group comparisons of children with specific language impairment, children with cochlear implants (CI), 
and second-language (L2) learners could provide important information about the relative performance of groups of learners who might be at-risk for language development because of these kinds of early experience. She argued further that such comparisons could provide insights into the role of different types of early language experience for language learning more generally. Comparative studies make it possible to obtain information about each group that cannot be obtained by studying each group alone, and thus could be particularly useful to gain insight into the unexplained individual variations in language acquisition that often characterize at-risk as well as other language learners. In a related vein, a recent review by Pierce, Genesee, Delcenserie, and Morgan (2017) highlighted the importance of multi-group comparisons between children with different types of early language experiences for understanding the factors that mediate variation in language learning in general. They argued that we can better identify the full range of factors that might influence language learning by comparing groups of learners with clearly identifiable differences in early language experiences. Accordingly, they reviewed evidence from studies of children who experienced early delays in exposure to language (internationally adopted (IA) children and children born profoundly deaf who had cochlear implants), as well as children with impoverished early language input (learners with CIs and children with repeated bouts of otitis media). Their review found that children who had experienced delays and/or interruptions in language exposure early in life, or who had difficulties accessing, perceiving, or processing linguistic input during the first months of life, differed in their language learning outcomes from infants with typical early language experiences. However, they were unable to compare the relative outcomes of these groups because their review was a secondary analysis of existing studies that involved different assessment methods and learners who were not necessarily comparable because they were not matched on critical factors, such as age, gender, and socioeconomic status (SES).

To our knowledge, there have been no direct multi-group comparisons of the differences and similarities in language learning outcomes of different types of at-risk learners (except Paradis \& Crago, 2000, on first- (L1) and second-language learners with and without SLI). As a result, we have limited understanding of diverse groups of at-risk children and, in particular, of whether they experience the same areas and magnitude of vulnerability in language development relative to one another. A direct comparison of children who are at-risk for language learning using the same assessment instruments would provide important insight into (a) whether they experience the same areas of vulnerability in language development and (b) where their vulnerabilities are of the same magnitude. In the present study, children from three at-risk groups were include; children with SLI, children born from hearing parents who received cochlear implants, and internationally adopted children. Two typically-developing (TD), or at least, not at-risk, groups were also included; TD monolinguals and TD L2 learners. The latter group was added to control for delay without prior mitigating circumstances, that is, loss of the first or birth language (as in the case of IA children), absence of and/or impoverished early language input (as in the case of children born deaf), and genetically related difficulties in processing early language input (as in the case of children with SLI). Comparisons between the IA and CI groups allowed us to examine the effects of delayed language exposure with and without early sensory/auditory input. A group of L2 learners was included in order to explore the potential influence of language attrition on the language development of IA children in comparison to that of L2 learners who experience 
delayed exposure to a new language but retain their L1. We also thought that early L2 learners would represent an interesting additional group to compare to the IA and CI groups - given that these three groups all experience variants of early delay in onset of language exposure. Inclusion of a group of children with SLI allowed us to compare the influence of early language-processing difficulties without delay, difficulties that are widely believed to be due to underlying genetic factors in contrast to the IA, CI, and L2 groups, who all experience some form of delayed language exposure. TD monolinguals matched on chronological age were included in order establish a common frame of comparison for the other groups.

Although there is within-group variation in the early language learning environments of each of the groups of interest in this study, it is also the case that children in each of these at-risk groups have some common experiences that have been shown to distinguish them from more typically developing children. All children with CIs experience a period during early development with no or very limited auditory input/exposure to language; all IA children experience a language switch early in life and most experience abrupt discontinuation in exposure to and acquisition of the birth language; and all children with SLI experience difficulties processing linguistic input from birth. Therefore, while there are likely individual differences within each of these groups, similarities and differences between these groups of children have been studied by researchers with respect to certain common and distinct experiences with language early in development. Moreover, the children in each of these groups share background or learner characteristics that are widely used for clinical, diagnostic, and other practical purposes, and thus comparing their language learning directly is potentially useful. In the long run, greater attention to within-group variations in early experiences is desirable. With this caveat in mind, we now review research relating to the early language experiences of each of these groups, and how these experiences have been linked to later language outcomes.

\section{Children with cochlear implants}

Prior to implantation, children who are born with profound bilateral sensorineural hearing loss are unable to detect the acoustic-phonetic cues that are essential for speech recognition (Niparko et al., 2010) and to perceive auditory sensory information and, as a result, to take part in experiences involving spoken language communication (e.g., Geers, Brenner, \& Davidson, 2003). They are of interest in this investigation because they are a case of delayed language exposure without prior sensory input. It is important to note that, although children who are born deaf may be fitted with hearing aids prior to implantation, their access to auditory, and particularly linguistic, input is severely limited even with hearing aids (e.g., Niparko et al., 2010). In fact, none of the children with CIs in the present study had used hearing aids prior to or after implantation.

The intervention of choice for parents of congenitally deaf children is cochlear implantation. CIs directly stimulate the auditory nerve by transforming acoustic cues into an electrical code, allowing the brain to perceive and process sound (O’Donoghue, Nikolopoulos, \& Archbold, 2000). Thus, CI makes it possible for deaf children to benefit from improved access to speech and environmental sounds that are necessary for learning spoken language (e.g., Kronenberger, Pisoni, Harris, Hoen, $\mathrm{Xu}, \&$ Miyamoto, 2013). Although universal auditory screening of the hearing of newborns reduces considerably the age when most deaf children receive 
implantation, some deaf children still receive their implant after 12 months of age, the closure of the sensitive period for phonological fine-tuning (Pierce et al., 2017). In addition, implanted children go through a period of time, usually months, during which the implant is not fully operational and, as a result, they have no, or very limited, access to oral language input immediately after implantation.

Studies indicate that, on average, children with CIs score lower than their TD hearing peers on a variety of measures of language ability; a difference in performance that is often around one standard deviation (Nittrouer, Lowenstein, \& Holloman, 2016). Lags have been reported for standardized tests and parent reports assessing speech perception (e.g., Nicholas \& Geers, 2007), expressive and receptive vocabulary and grammar (e.g., Chilosi et al., 2013), as well as sentence recall (Kronenberger, Pisoni, Henning, Colson, \& Hazzard, 2011). The few studies that have looked at CI children's performance on tests of morphology, phonology, and phonological processing as well as morphosyntax also report significant difficulties in comparison to test norms and to TD controls (e.g., Caselli, Rinaldi, Varuzza, Giuliani, \& Burdo, 2012; Chilosi et al, 2013; Mayberry, 2007; Tomblin, Harrison, Ambrose, Walker, Oleson, \& Moeller, 2015). Although the speech and language abilities of CI children have been found to improve with age, suggesting developmental growth, their language learning is usually significantly slower than that of TD children, and their language abilities remain below age-appropriate levels throughout development (e.g., Kronenberger et al., 2013). This has been found to be especially true for measures of spoken language expression and comprehension and vocabulary (e.g., Niparko et al., 2010).

Several factors are thought to explain the language difficulties experienced by children with CIs, including duration of CI use (Kronenberger et al., 2013; Nicholas \& Geers, 2013) and unilateral vs. bilateral implantation (Nittrouer et al., 2016). Of particular relevance to the present study, the most important factor known to influence implanted children's language development is age at implantation. In comparison to children more than 12 months of age at the time of implantation, children who are implanted before 12 months of age achieve higher levels of language comprehension and expression (Nicholas \& Geers, 2013; Niparko et al., 2010), have a larger range of auditory perceptual discrimination abilities (e.g., Nicholas \& Geers, 2013), have a steeper growth curve (Dettman, Pinder, Briggs, Dowell, \& Leigh, 2007), and are more likely to attain normative levels of ability (Nicholas \& Geers, 2013) and to exhibit better speech perception and intelligibility (Vlastarakos, Poikas, Papacharalampous, Exadaktylou, Mochloulis, \& Nikolopoulos, 2010). These advantages are thought to arise because children who are exposed to sound before 12 months of age can benefit from better parent-child communicative interactions, are within the normal age range for the development of pre-communicative behaviors and for babbling onset, and are exposed to sound before the closure of the sensitive period for phonology (Vlastarakos et al., 2010). In contrast, children who are implanted at older ages have no auditory input during the sensitive period for phonology, and this delayed exposure to auditory input is thought to lead to incomplete or underspecified language-specific phonological representations for auditory/spoken words in memory, and thus to speech-language lags (e.g., Bouton, Colé, Serniclaes, Duncan, \& Giraud, 2015; Pierce et al., 2017; see also Kuhl, Ramirez, Bosseler, Lin, \& Imada, 2014, for a description of children's phonetic development and its mechanisms). Also, because CI children have such restricted access to language at the earliest stage of language acquisition, they often 
do not develop the foundations for typical communication skills, pre-communicative behaviors and babbling in particular (e.g., Geers et al., 2003).

\section{Internationally adopted children}

Like children with CIs, IA children also experience delayed exposure to language insofar as they are exposed to a language that ultimately becomes their only language after adoption, usually around 12-24 months of age in the case of children adopted from China. However, unlike children with CIs, IA children have access to language from birth, although they usually experience behavioral attrition of that language soon after adoption (Delcenserie, Genesee, \& Gauthier, 2013). This raises the question of the importance of retention of the birth language for the children's acquisition of the adopted language, a point we return to later.

Studies of the language development of IA children from East Asian countries that have used standardized tests and parent reports normed on TD non-adopted children have shown that IA children usually perform within test norms as early as 12-24 months after adoption (Scott \& Roberts, 2016), indicating a great deal of resilience on the part of IA children (Rutter, 2012). At the same time, however, studies that have compared IA children to non-adopted children matched on variables that have been linked to language learning - such as SES, age, and gender - report that IA children experience some relative weaknesses in language development (Delcenserie et al., 2013; Delcenserie \& Genesee, 2014) in domains related to expressive and receptive language and vocabulary as well as sentence recall. Similar to studies with children with CIs, only a few studies have looked at IA children's phonological and morphosyntactic abilities in depth. Nevertheless, there is some evidence that their phonological processing abilities are below age norms (Scott, Roberts, \& Krakow, 2008).

In terms of developmental growth, IA children's language abilities increase with age, but weaknesses in language outcomes have been found to persist over time - during preschool and into the school years and even into adulthood (e.g., Delcenserie \& Genesee, 2014; Hyltenstam, Bylund, Abrahamsson, \& Park, 2009). Evidence suggests that the magnitude of their language weaknesses may even increase with age, particularly with respect to receptive grammar and sentence recall (Delcenserie \& Genesee, 2014).

Several studies have examined potential explanations for IA children's language weaknesses. Delcenserie and Genesee (2014) examined IA children from China who were adopted between ages $0 ; 6$ and 2;0 and who were between nine and twelve years of age at the time of testing. The IA children were compared to TD children matched on age, gender, and SES. They found that the IA children performed significantly lower than the controls on diverse measures of language ability, including vocabulary and grammar. Given that the IA children benefited from nine years and seven months of exclusive exposure to French, on average, the results of this study suggest that insufficient exposure to the adopted language is an unlikely explanation of adoptees' difficulties. Yet other evidence suggests that IA children's weaknesses cannot be attributed to the quality of input to the adopted language that they receive. In a study of the interactional styles of parents of IA children in comparison to matched monolingual control children, Pierce, Genesee, Gauthier, and DuBois (2014a) found that both adoptive mothers and fathers engaged in more joint attention episodes with their adopted children and produced more utterances within these joint attention episodes than birth parents with their children, suggesting that IA children receive sufficient and adequate input. 
In an fMRI study of IA children, Pierce, Klein, Chen, Delcenserie, and Genesee (2014b) compared the activation patterns of IA children from China, native speakers of Chinese who acquired French as a second language at the same time as the IA children, and monolingual French speakers. The participants, who were between ten and seventeen years of age at the time of testing, were scanned while discriminating Chinese pseudo-words that differed in tone. They found that the native Chinese speakers who had acquired French as an L2 recruited left-hemisphere language regions (e.g., superior temporal gyrus). Likewise, the IA children also recruited left-hemisphere temporal regions when discriminating between the pseudo-words in Chinese. In contrast, the monolingual native speakers of French recruited right-hemisphere regions. These findings indicate that there had not been total neurocognitive attrition of the birth language among the IA participants. In other words, since the bilingual and IA children showed the same results, attrition cannot explain the general language performance of the IA children on the French language tests. In a subsequent study by Pierce, Chen, Delcenserie, Genesee, and Klein (2015), the same participants were scanned while performing an n-back task using French pseudo-words - a measure of phonological working memory (PWM). They found that all groups activated regions associated with phonological working memory processing, but that the French monolinguals activated the left inferior frontal gyrus and the left anterior insula, regions associated with PWM processing, more strongly than the adoptees and the bilinguals. The bilinguals and adoptees, on the other hand, activated regions associated with nonverbal memory and cognitive control processes, that is, the right superior and middle frontal gyri. This indicates that the neurocognitive systems used by IA children to process French are more similar to those of L2 learners than to those of TD monolingual children, and again indicate that it is delayed exposure to French and not attrition of the birth language that underlies the French language results of the IA children.

\section{Children with specific language impairment}

Specific language impairment is a neurodevelopmental disorder that affects approximately $7 \%$ of children: about $6 \%$ of girls and $8 \%$ of boys (Conti-Ramsden \& Durkin, 2011; Leonard, 2014). SLI is usually defined as a failure to make normal progress in language in the absence of other impairments, such as hearing, intellectual, neurological, social, and/or emotional problems (Leonard, 2014). SLI is a long-term disorder that affects children from birth (see Leonard, 2014, for a detailed review), arguably a reflection of its underlying genetic etiology, that changes with age and development, both within and across linguistic domains (Bishop, 2006). Although there is currently no consensus on the specific cause(s) of the language learning difficulties of children with SLI, there is some agreement that these are linked to their difficulty processing linguistic input. More specifically, it has been proposed that children with SLI have a neurocognitive impairment involving portions of the frontal/basal ganglia circuits that results in difficulties processing linguistic input (e.g., Leonard, 2014; Lum, Conti-Ramsden, Page, \& Ullman, 2012). Children with SLI were included in the present study to examine the possible impact of a language-specific genetic impairment in comparison to other types of risk factors. Specifically, although SLI children benefit from early language exposure, they are unable to fully benefit from this early exposure due to their difficulties processing linguistic input. 
In terms of language development, SLI children do not reach developmental milestones such as production of first words and word combinations on schedule, in comparison to TD children, and are slower than TD children from the beginning of the language learning process (Conti-Ramsden \& Durkin, 2011). Although their language abilities are delayed, their pattern of language growth is often similar to that of their TD peers (Conti-Ramsden \& Durkin, 2011). The severity of their impairment seems nonetheless stable since, with age, they often do not change in comparison to their hearing peers (Conti-Ramsden \& Durkin, 2011).

Children with SLI exhibit a heterogeneous profile of language difficulties. Overall, they tend to perform more than one standard deviation below age norms on standardized measures of language ability (e.g., Lum et al., 2012), and they exhibit difficulties in a wide range of linguistic domains, including expressive and receptive vocabulary and syntax (e.g., Conti-Ramsden, Crutchley, \& Botting, 1997), linguistic awareness, as measured by grammaticality judgment tasks, and sentence comprehension (e.g., van der Lely, 1996). SLI children's morphosyntactic abilities have been the subject of much attention, since morphosyntax has been shown to be a particularly vulnerable area of development and, in fact, it is often used as a marker of SLI. The aspects of morphosyntax that are affected in children with SLI are often language-specific and involve their ability to use inflections and derivational morphemes (Conti-Ramsden et al., 1997). The phonological difficulties reported in samples of children with SLI have often been found to involve immature phonological processes, including simplification and fronting (Conti-Ramsden et al., 1997; Conti-Ramsden \& Durkin, 2011). Children with SLI commonly have difficulties on tests of sentence recall - a test that appears to be a sensitive marker of SLI (e.g., Thordardottir \& Brandeker, 2013).

\section{Second-language learners}

Second-language (L2) learners, also sometimes called 'successive bilinguals', acquire a second language after the first language. There is no consensus on how early in development the acquisition of an additional language constitutes L2 learning in contrast to simultaneous acquisition of more than one language. Although three years of age has often been used as a cut-off (e.g., Meisel, 2004), recent evidence by Pierce et al. (2014b, 2015, 2017) suggests that one year after birth might be more appropriate. Since Pierce et al. (2017) provide evidence of neurocognitive differences between L1 learners and children who had acquired the same language after only one year of age, we used one year of age as a cut-off to identify our L2 learners.

Generally speaking, evidence suggests that the patterns and rate of language acquisition are highly similar in young L2 learners and TD monolinguals learning the same languages (e.g., Paradis, 2006; Thordardottir, 2011). This appears to be true not only for vocabulary but also for morphosyntax (e.g., Thordardottir, 2011, 2015). However, there are wide individual differences in L2 acquisition, and it is now well known that L2 learners' language outcomes depend on several factors, including motivation, aptitude, personality characteristics (e.g., assertiveness), cognitive abilities (e.g., working memory), first-language typology, and SES (see Paradis, 2006, for a review). Quality and quantity of L2 input have also received a lot of attention in this regard. Research clearly shows that exposure to rich and diverse vocabulary and grammatical forms has a positive impact on L2 outcomes, including but not limited to lexical growth (e.g., Paradis, 2006) and rate of morphosyntactic development (e.g., 
Jia, 2003), especially past tense verb forms, plural marking - s, and gender marking (e.g., Nicoladis \& Marchak, 2011; Nicoladis, Palmer, \& Marentette, 2007), as well as sentence recall (Thordardottir \& Brandeker, 2013).

Of particular interest to the present study, there is evidence that even relatively short delays in the onset of L2 acquisition can result in non-native-like language performance (e.g., Hyltenstam, 1992). For example, Abrahamsson and Hyltenstam (2009) examined native speakers of Spanish who had acquired Swedish as an L2 at different ages (less than 1 year of age and up to more than 47 years; $n=195$ ). Of particular interest, only a minority of the L2 learners who were judged as native speakers were able to perform within the native-speaker range on these demanding tests of language ability. This was true even of participants who had acquired Swedish before five years of age - fewer than $10 \%$ of these early L2 learners performed like native speakers of Swedish more than 20 years later. Other studies have similarly reported early age-of-acquisition effects in several domains of language ability, including morphosyntax (e.g., Jia, 2003) and phonology (e.g., Colantoni \& Steele, 2006).

Young L2 learners were included in the present study because they experience delayed onset of exposure to the L2. However, unlike IA children, they continue to acquire and use their L1 after the onset of L2 acquisition, and thus divide their learning time between two languages. Unlike children with CIs, they have auditory/ sensory input of a linguistic nature prior to the onset of L2 acquisition. Thus, inclusion of a group of L2 learners who had benefited from extensive, high-quality input in the L2 allowed us to examine the effects of delay with and without linguistic input after birth (L2 learners and children with CIs) and of delay with L1 retention versus delay with attrition of the birth language (L2 learners and IA children).

\section{The present study}

Overall, and generally speaking, extant evidence suggests that young language learners who experience delayed exposure to language due to deafness and/or international adoption and children who have limited ability to benefit from early linguistic input due to genetic factors exhibit weaknesses in language acquisition as a result of these early language experiences and that these weaknesses persist into adulthood. It is difficult to predict the relative level of performance of each group with certainly because no direct comparisons of these groups have been made using common assessments, as noted earlier. It might nonetheless be expected that the children with CIs and SLI would perform relatively less well than the IA group because the former experience no or impoverished linguistic input from birth, in contrast to the IA children who, other things being equal, experience normal input from birth and, in fact, prior to birth. Also, Pierce et al.'s (2014b) finding that IA and L2 learners engage the same neurocognitive systems when processing their L2 would predict that the IA children would perform similarly to the L2 learners. The extant evidence, reviewed earlier, indicates that, generally speaking, these groups exhibit weaknesses in all domains of language - phonological, lexical, and morphosyntactic, although weaknesses in specific domains are more salient in some groups than others - e.g., morphosyntax in the case of children with SLI and phonological processing in the case of children born deaf. Thus, for present purposes, we expected that direct comparisons would indicate relative weaknesses in all domains of assessment (described shortly) in each group of interest relative to the TD monolingual and L2 learner groups. 


\section{Methods}

\section{Participants}

Seventy-five children between ages 5;0 and 7;3 were included in the study. All children spoke French either as their only language (monolinguals (MON), IA, CI, and SLI children) or as a second language (L2 learners). Each group included fifteen children, 9 girls and 6 boys (see Table 1 for the complete demographic information on the participants). All groups were matched on chronological age, gender, and socioeconomic status (i.e., maternal level of education, paternal level of education, and family income), factors that correlate with language and cognitive outcomes (e.g., Hoff, 2006). The IA children, the children with CIs, and the L2 learners of French were also matched on age at the onset of exposure to French and length of exposure to French.

Exclusionary criteria for all groups included: presence of psychiatric, cognitive, or neurological antecedents; intellectual deficiency; premature birth; and serious health, motor, or behavior problems, including attention deficit hyperactivity disorder. The IA children, the children with SLI, and the children with CIs spoke only French and had less than $25 \%$ exposure to another language; the L2 learners had had at least $45 \%$ exposure to French on a daily basis at the time of testing, ensuring that they had had sufficient exposure to the language to have acquired advanced levels of proficiency (Thordardottir, 2011, 2015). In fact, their results on the French language tests we administered confirm that this group had high levels of proficiency. All the children, except the children with CIs, had typical hearing abilities, and all except the SLI and CI children had typically developing language abilities.

\section{IA children}

The IA children were recruited through adoption agencies in the region of Montreal. They were between ages $5 ; 4$ and $7 ; 0$ at the time of testing $(M=6 ; 1 ; S D=0.53)$ and had had a mean length of exposure to French of $5 ; 1 \quad(3 ; 5-6 ; 1 ; S D=0.69)$. They had been adopted into monolingual French-speaking families between ages $0 ; 7$ and 2;0 $(M=0 ; 11 ; S D=0.46)$.

To rule out general developmental problems due to severe pre-adoption impoverishment as explanations of their post-adoption language results, only IA children from East Asian countries were recruited, because research has shown that, as a group, they often have age-appropriate cognitive abilities and socio-emotional development suggesting minimally harmful pre-adoption experiences (Pomerleau et al., 2005; Rice, Jackson, Mahoney, \& Tan, 2016). This made it possible to argue that their post-adoption language outcomes were probably due primarily to language-related factors and, in particular, delayed exposure to the adopted language and/or attrition of the birth language independently of other variables that can negatively impact general development.

The countries of adoption included China $(n=5)$, South Korea $(n=3)$, Vietnam $(n=3)$, the Philippines $(n=2)$, Thailand $(n=1)$, and Taiwan $(n=1)$. Twelve children had been institutionalized prior to adoption whereas three had been living in foster care families. All the adoptive parents reported that, in their opinion, their child either received good pre-adoptive care $(n=10)$ or had suffered from only mild deprivations $(n=5)$. Parent reports also revealed that most children were healthy at the time of adoption $(n=9)$; but, mild health problems $(n=3)$, socio-emotional problems $(n=5)$, motor problems $(n=1)$, and language problems $(n=3)$ were 
Table 1. Demographic Information

\begin{tabular}{|c|c|c|c|c|c|c|c|c|c|c|}
\hline & IA & $\mathrm{Cl}$ & SLI & L2 & MON & $F$ & $d f$ & $\chi^{2}$ & $p$ & $\eta^{2}$ \\
\hline $\begin{array}{l}\text { Age of onset of exposure (in years; } \\
\text { months, } M \text { and } S D \text { ) }\end{array}$ & $1 ; 0(.39)$ & $1 ; 0(.73)$ & & $1 ; 3(.50)$ & & 1.31 & $(2,42)$ & & .29 & .06 \\
\hline $\begin{array}{l}\text { Length of exposure (in years;months, } \\
M \text { and } S D \text { ) }\end{array}$ & $5 ; 1(.66)$ & $4 ; 10(.89)$ & & $4 ; 11(.62)$ & & 0.44 & $(2,42)$ & & .65 & .04 \\
\hline Maternal level of education ( $n$ and \%) & & & & & & & 8 & 3.60 & .89 & .04 \\
\hline College & 2 & 4 & 4 & 4 & 2 & & & & & \\
\hline University & 11 & 9 & 8 & 9 & 12 & & & & & \\
\hline Paternal level of education ( $n$ and \%) & & & & & & & 8 & 2.18 & .98 & .02 \\
\hline High School & 4 & 3 & 5 & 3 & 3 & & & & & \\
\hline $20000-39999$ & 1 & 4 & 4 & 3 & 2 & & & & & \\
\hline $40000-59999$ & 0 & 0 & 0 & 0 & 0 & & & & & \\
\hline $60000-79999$ & 1 & 2 & 3 & 3 & 2 & & & & & \\
\hline $80000-99999$ & 2 & 2 & 3 & 2 & 2 & & & & & \\
\hline More than 100000 & 11 & 7 & 5 & 7 & 9 & & & & & \\
\hline
\end{tabular}

Notes. $\mathrm{Cl}$ = children with cochlear implants; IA = internationally adopted children; $\mathrm{L} 2$ = second-language learners; MON = typically developing monolingual French-speaking children; $\mathrm{SLI}=$ children with specific language impairment. For the IA children, the age of onset of exposure to French corresponds to the age at adoption. 
mentioned by a few adoptive parents - with some parents reporting more than one problem for their child. All adoptive parents reported that these difficulties had either totally disappeared or significantly decreased by the time of testing. Only one adoptee was reported to be receiving speech-language therapy at the time of testing, but the child's parents expressed only mild concerns about the language development of their child.

\section{Children with cochlear implants}

The children with CIs were recruited from rehabilitation centers in Montreal. As a group, these children were between ages $5 ; 1$ and $7 ; 3$ at the time of testing $(M=6 ; 2$; $S D=0.76)$ and had been exposed to oral French for $4 ; 10(3 ; 7-6 ; 4 ; S D=0.89)$. All were reported to have bilateral profound sensorineural hearing loss at birth due either to genetic causes $(n=2)$, a malformation $(n=2)$, or unknown causes $(n=11)$. Note that, although the nature of the deaf children's malformations was unknown to the parents, these malformations did not impede children from being implanted. They received a diagnosis of deafness around age $0 ; 11$, on average $(0 ; 1-2 ; 0 ; S D=$ 0.73). They all had parents with normal hearing. When questioned, the parents reported that they did not know what type of testing was performed to diagnose the hearing loss of their child and/or whether a behavioral audiogram had been performed prior to implantation.

Twelve of these children received bilateral cochlear implants; among these children, five received their first implant on the left side while the others had their first implant on the right side. These children were implanted for a first time at age 1;0 and for a second time at age $2 ; 7$, on average (first implant: $0 ; 8-2 ; 0, S D=0.74$; second implant: $1 ; 3-4 ; 6, S D=1.17)$. Of the three children who had only one implant, two had an implant on the left side and one had an implant on the right side. All the children were implanted in the same two children's hospitals and received implants of similar types (Nucleus 4, Nucleus 5, Nucleus 6, Nucleus Freedom, and Nucleus C810). Parents were unable to recall the type of intervention their child had received prior to implantation.

In terms of communication abilities prior to implantation, parents reported that their children were unable to communicate, to produce sounds, and/or to communicate with signs. Accordingly, these children were tested only using spoken language. In addition, parents reported that the children did not have any auditory ability prior to the activation of their implant(s) and that none of them had used hearing aids prior to implantation. These children were all able to produce words in French two months after their first implantation, on average $(0 ; 1-0 ; 5, S D=0.13)$. As is usually the case for children who receive a diagnosis of profound deafness, all the participants were receiving speech-language therapy. At the time of testing, the children had been followed by speech-language therapists, on average, for $3 ; 9(1 ; 7-$ $6 ; 7 ; S D=1.30)$. Their parents reported having either no concern for the language development of their child $(n=5)$, mild concerns $(n=3)$, or moderate concerns $(n=7)$. The major concern reported by parents was the fear that their child would not be able to catch up to typical language abilities despite having already made good progress.

\section{Children with SLI}

The children with SLI were also recruited through the same rehabilitation centers as the CI children. They were aged between $5 ; 2$ and $7 ; 0$ at the time of testing $(M=6 ; 2 ; S D=$ 0.65 ). They received a diagnosis of SLI by a licensed speech-language therapist around 
age $3 ; 2(2 ; 0-4 ; 0$ years; $S D=0.81)$ and had been receiving speech-language therapy for $3 ; 1(0 ; 8-5 ; 0 ; S D=1.06)$. Unfortunately, parents were unable to provide more detailed information about their child's language abilities at the time of their diagnosis. However, they reported their child's specific language difficulties at the time of testing, including phonology $(n=8)$, vocabulary $(n=5)$, syntax $(n=6)$, morphology $(n=4)$, receptive language $(n=1)$, and verbal memory $(n=1)$, with most children experiencing difficulties in more than one of these areas. These difficulties were reported to persist at the time of testing. Two parents reported having no concern for the language development of their child, but the others reported having either mild $(n=6)$ or moderate concerns $(n=7)$.

\section{L2 learners of French}

The L2 learners were recruited through a suburban immersion school outside Montreal. The children were aged between $5 ; 7$ and $7 ; 2$ at the time of testing $(M=6 ; 2 ; S D=0.65)$ and all had French as an L2 and English $(n=10)$, Arabic $(n=1)$, Spanish $(n=2)$, or Mandarin $(n=2)$ as their first language. According to parental report, the children had first been exposed to French intensively at home beginning around age $1 ; 3$, on average $(0 ; 6-2 ; 0 ; S D=0.50)$. Thus, they had been exposed to French as a second language intensively for $4 ; 11$, on average $(4 ; 1-6 ; 6 ; S D=0.62)$. The parents of all L2 children were proficient in French and were able to provide them with high-quality input at home. Detailed parental reports made it possible to determine that, on average, the L2 learners had daily exposure to French of about 49\% (45-65\%; $S D=$ 7.66). None of these participants was receiving speech-language therapy at the time of testing, although one child had been evaluated in the past. Parents expressed either mild $(n=2)$ or no $(n=13)$ concern for the language development of their child.

\section{Typically developing monolingual French-speaking children}

The monolingual speakers of French were recruited from a French language school in suburban Montreal. These participants were aged 6;2, on average, at the time of testing $(5 ; 0-7 ; 1 ; S D=0.70)$. None had been evaluated by a speech-language therapist or received speech-language therapy. Their parents all expressed no concern for their language development.

The present study was approved by the Comité d'éthique à la recherche des établissements (CÉR) du Centre de Recherche Interdisciplinaire en Réadaptation (CRIR) as well as by McGill University Research Ethics Board.

\section{Questionnaires}

Parents were asked to complete a Developmental Questionnaire (Delcenserie et al., 2013; Delcenserie \& Genesee, 2014) that collected information about the participants' health, general development, behavior, and socio-emotional adjustment. This questionnaire was modified in order to collect information specifically about the diagnosis, abilities, and general history of the IA children, the children with SLI, and the children with CIs.

The Child Behavior Checklist (CBCL; Achenbach, \& Rescorla, 2000) was used to assess participants' socio-emotional adjustment. This questionnaire is a parent report that assesses children's behavior and social competence at home (Delcenserie \& Genesee, 2014). Depending on their child's age, the parents either filled out the 
version for children aged between $1 ; 6$ to 5;0, or the version for children between 6 and 18 years of age.

A Language Exposure Questionnaire (Delcenserie \& Genesee, 2014) was also completed by parents in order to ascertain the children's language exposure, and thus to make sure that the L2 learners of French had extended and intensive exposure to French and to ensure that the other groups had not had more than $25 \%$ of exposure to an L2. The Language Exposure Questionnaire was also administered to ascertain if the children's language exposure had changed from birth to the time of testing. Because the participants were all in the upper levels of elementary school and living in Quebec, they had all had some minimal exposure to English as a second language in school (i.e., approximately 30-60 minutes, three times a week).

\section{Assessment materials}

All the measures used in the present study included norms for French-speaking children, with the exception of the Expressive One-Word Picture Vocabulary Test (EOWPVT; Brownell, 2000), for which English norms were used; results on the latter should thus be interpreted with caution.

\section{Control measures}

Non-verbal fluid reasoning was assessed using the Matrices subtest of the Wechsler Nonverbal IQ test (Wechsler \& Naglieri, 2006). This test started with the experimenter presenting each participant with pictorial directions and, during test, the participants were asked to select the missing portion of a matrix from among a set of five options.

The Attention Auditive subtest of the NEPSY (A Developmental Neuropsychological Assessment; Korkman, Kirk, \& Kemp, 2007) was included as a measure of sustained selective attention. In this test, the children were presented with four colored circles (blue, red, yellow, and black) while listening to a string of words, including color words, presented on a tape-recorder (Sony ICD-SX733) equipped with a speaker. They were instructed to touch the red circle each time they heard the word 'red'.

The Coding subtest of the Wechsler Nonverbal IQ test (Wechsler \& Naglieri, 2006) was used to assess speed of processing. Because this ability has often been found to influence language development, it was included as a control measure. As was done for the other subtests of the Wechsler Nonverbal IQ test, the experimenter started by showing pictorial instructions to the participants. The participants then had to copy symbols that corresponded to a given form (e.g., a dash for a triangle). Participants had to copy as many symbols as possible in two minutes. A score of one was given for each symbol correctly copied.

\section{Language tests}

A French adaptation of the Expressive One-Word Picture Vocabulary Test (Brownell, 2000) was used to assess expressive vocabulary. The adaptation of this test was carried out at a large speech and language pathology department of a children's hospital in Montreal. The test evaluates children's ability to make word-image associations by requiring children to name a series of images presented by the experimenter.

Receptive vocabulary was assessed using the Échelle de Vocabulaire en Image Peabody (EVIP; Dunn, Theriault-Whalen, \& Dunn, 1993), which is normed for 
French-speaking Canadians. In this test, the children had to point to the image, among a set of four, that best represented a word spoken by the experimenter (Delcenserie \& Genesee, 2014).

Several subtests of the Clinical Evaluation of Language Fundamentals for French speaking Canadians (CELF-CDN-F; Semel, Wiig, \& Secord, 2009) were also administered, namely, the Formulation de phrases 'Formulated Sentences', the Structure de phrases 'Sentence Structures', the Morphologie 'Word Structure', and the Conscience phonologique 'Phonological Awareness' subtests. The Formulated Sentences subtest was used to assess participants' ability to orally produce sentences that are semantically and syntactically appropriate. It was used as a measure of expressive language. In this test, the children were shown images and presented orally with a word. They then have to generate a complete sentence by using the word previously heard and by taking the context of the image into account. The test was designed so that the words that are presented by the experimenter require the participant to produce sentences that increase in length and complexity.

The Sentence Structures subtest was used to evaluate the children's ability to interpret sentences presented orally. The experimenter presented the children with sentences that increased in length and syntactic complexity and the children had to choose the image, among a set of four, that best corresponded with the sentence. This test was used as a measure of receptive language.

The Word Structure subtest assessed the children's ability to correctly apply word structure rules by marking inflections, derivations, and comparisons, and also to use correct pronouns in a given context. This test was used to evaluate participants' knowledge of morphology. The test was comprised of images and orally presented sentence fragments that the children had to complete. For example, the experimenter showed an image of two boys, one who was standing and one who was sitting. The experimenter then said Le garcon est debout et ce garcon est ... 'The boy is standing and this boy is ...'. The child was expected to complete the sentence using the targeted structure - 'sitting'.

The Phonological Awareness subtest included 11 different tasks. These tasks evaluated the children's knowledge of the sound structure of French, their ability to correctly manipulate the sounds of French through rhyme awareness and production and phoneme segmentation, as well as the identification and manipulation of syllables and phonemes (Semel et al., 2009). For a complete description of the administration procedure of the 11 tasks of this subtest, we refer the reader to the CELF-CDN-F Manual (Semel et al., 2009). As per the CELF-CDN-F manual, a global score for all 11 subtests was entered.

Measures of sentence recall, although ostensibly indicators of verbal memory ability (Alloway \& Gathercole, 2005) and more specifically the functioning of the episodic buffer (Vugs, Hendriks, Cuperus, \& Verhoeven, 2014), have also been found by an extensive number of studies to correlate with language ability (e.g., Klem, Melby-Lervåg, Hagtvet, Solveig-Alma, Gustafsson, \& Hulme, 2015). Indeed, measures of sentence recall are often used as a marker of SLI (e.g., Thordardottir \& Brandeker, 2013). For this reason, we included this measure in our battery of tests. We used the French version of the English Recalling Sentences subtest of the Clinical Evaluation of Language Fundamentals - Revised (CELF-R; Semel, Wiig, Secord, \& Sabers, 1987) in order to facilitate comparison of the present findings with results from our previous studies on IA children (see Delcenserie et al., 2013, and Delcenserie \& Genesee, 2014). This test assesses participants' ability to repeat sentences that 
increase in length and syntactic complexity. It includes 32 sentences, but the test is interrupted when a participant obtains five consecutive scores of zero. Scores of zero are assigned when four or more errors are made in the repetition of a single sentence. Participants were given three points for each sentence correctly recalled, two points for sentences in which only one error was made, and one point when two or three errors were made during repetition.

\section{Procedure}

Before testing began, the experimenter explained the study to parents and showed them the questionnaires and answered questions. Parents were then asked to sign the consent form. Parents who consented to participate were then asked to complete the Developmental Questionnaire, the Language Exposure Questionnaire, and the age-appropriate CBCL.

Each participant was tested individually in their home. When the parents asked to be present during testing, they were asked to remain quiet and to refrain from providing help. Testing was done in either three 1-hour sessions or two 90-minute sessions, depending on the fatigue level of the child as well as on the parents' schedule. Pauses were taken as necessary. The order of administration of the tests was counterbalanced to avoid order and/or fatigue effects. In addition to the present language tests, tests of verbal and non-verbal memory were also administered and will be reported in a follow-up paper.

\section{Results}

\section{Demographic information}

Since no significant differences were found between the boy and girls on any of the tests, results were collapsed across gender. Similarly, no significant differences were found between countries of origin for the IA children, between children with unilateral or bilateral implantation, or between first languages for the L2 learners on any of the variables.

A one-way independent-groups analysis of variance (ANOVA; $\alpha=.05$ ) was carried out to compare the groups on chronological age. The analysis revealed no significant differences (see Table 1). The IA children, the children with CIs, and the L2 learners were similarly compared on age at the onset of exposure to French as well as on length of exposure to French. Again, no significant differences were found.

Chi-square tests were performed to compare the groups on maternal level of education, paternal level of education, and family income; no significant differences on any of these variables were found, indicating that the groups were well matched on SES.

\section{Socio-emotional adjustment}

A one-way independent-groups analysis of variance (ANOVA; $\alpha=.05$ ) was performed to compare the groups on the internalizing and externalizing subscales of the CBCL, as well as on total scores. As can be seen from Table 2, the results revealed no significant differences among the groups on any of these variables, suggesting that the groups exhibited similar socio-emotional adjustment. However, some children did perform 
in the borderline clinical range indicated by a score between 60 and 63 out of 100, while others performed within the clinical range and had a score above 63. Eight children performed in the borderline clinical range on the internalizing subscale, five on the externalizing subscale, and five on the total score of the CBCL. Slightly fewer children performed in the clinical range, that is, four on the internalizing subscale, three on the externalizing subscale, and four on the total score of the CBCL (for the distribution of the children with scores in or near the clinical range see Table 2). While the distribution of children with scores in or near the clinical range was not entirely even across groups, there did not appear to be a concentration of children with low scores in any particular group. In each of our subgroups, no significant differences were found between children who performed near or within the clinical range on the CBCL and the other children on any of the control and language measures.

\section{Control test and language test results}

A multivariate analysis of variance (MANOVA) was performed to compare the groups on the control measures, as well as the tests of language ability. Prior to data analysis, the appropriate assumptions were assessed. The design of the study controlled for independence of observations. Visual inspection of the histograms and Q-Q plots confirmed that the dependent variables were normally distributed, while examination of scatterplots confirmed linearity. Levene's and Box's $M$ tests confirmed that the assumptions of homogeneity of variance and covariances were met $(p>.05)$.

The effect of group membership was found to be statistically significant (Wilk lambda: $F\left(40.00,233.16=22.19, p<.001, \eta^{2}=.77\right)$. The groups were shown to differ significantly on all measures of language ability (see Table 3), even after using a Bonferroni correction to account for multiple comparisons $(p=.005)$. No significant differences were found between the groups on any of the control measures.

Tukey HSD post-hoc tests showed that the groups exhibited the same pattern of results on all language tests - specifically, the CI and the SLI groups did not differ significantly from one another, but both groups scored significantly lower than the IA and L2 groups (see Table 4). Of interest, the IA and L2 groups did not differ significantly from one another. All these groups, including the L2 learners, scored significantly lower than the MON children on all language tests.

The only exception to this pattern was the performance of the IA group on the Phonological Awareness subtest on which they performed significantly lower than the L2 learners. This is particularly interesting in light of fact that the IA children abruptly interrupted acquisition of their birth language when they started exposure to their adopted language and in light of Pierce et al.'s (2014a) finding that there were neural traces of the birth language during a phonological discrimination task.

\section{Comparison with test norms}

Table 5 summarizes the children's performance on each test compared to test norms. As mentioned earlier, because French norms were not available for the EOWPVT, English norms were used. As a result, it is important to exercise caution when interpreting these results. In general, the results indicate that the groups performed within the norms on the control measures. In terms of language ability, the IA group and the L2 group, on average, performed at the low end of the normal range whereas the MON group performed at the high end. It is important to note that the MON group was a 
Table 2. Performance of the Groups on Socio-Emotional Adjustment (CBCL)

\begin{tabular}{|c|c|c|c|c|c|c|c|c|}
\hline & IA & $\mathrm{Cl}$ & SLI & L2 & MON & $F(4,70)$ & $p$ & $\eta^{2}$ \\
\hline Internalizing ( $M$ and $S D$ ) & $51.20(8.32)$ & $50.33(7.69)$ & $53.40(6.46)$ & $48.87(7.48)$ & $47.73(11.83)$ & .97 & .43 & .05 \\
\hline Borderline clinical range $(n)$ & 1 & 1 & 3 & 2 & 1 & & & \\
\hline Clinical range $(n)$ & 1 & 1 & 0 & 0 & 2 & & & \\
\hline Externalizing ( $M$ and $S D)$ & $48.33(12.62)$ & $49.60(7.60)$ & $51.87(7.72)$ & $49.53(8.55)$ & $48.53(12.12)$ & .30 & .88 & .02 \\
\hline Borderline clinical range $(n)$ & 2 & 0 & 1 & 0 & 2 & & & \\
\hline Clinical range $(n)$ & 1 & 0 & 0 & 1 & 1 & & & \\
\hline Total score $(M$ and $S D)$ & $50.13(10.66)$ & $50.60(6.38)$ & $52.13(6.90)$ & $49.53(7.26)$ & $48.20(10.49)$ & .43 & .79 & .02 \\
\hline Borderline clinical range $(n)$ & 1 & 0 & 1 & 1 & 2 & & & \\
\hline Clinical range $(n)$ & 2 & 0 & 0 & 1 & 1 & & & \\
\hline
\end{tabular}

Notes. $\mathrm{Cl}=$ children with cochlear implants; $\mathrm{IA}=$ internationally adopted children; $\mathrm{L} 2$ = second-language learners; $\mathrm{MON}=$ typically developing monolingual French-speaking children; SLI = children with specific language impairment. The scores are out of 100. A performance in the borderline clinical range is between 60 and 63 . A performance in the clinical range is above 63 . 
Table 3. Performance of the Groups on the Control and Language Measures

\begin{tabular}{|c|c|c|c|c|c|c|c|c|}
\hline & $\begin{array}{c}\mathrm{IA} \\
M(S D)\end{array}$ & $\begin{array}{c}\mathrm{Cl} \\
M(S D)\end{array}$ & $\begin{array}{c}\text { SLI } \\
M(S D)\end{array}$ & $\begin{array}{c}\text { L2 } \\
M(S D)\end{array}$ & $\begin{array}{c}\text { MON } \\
M(S D)\end{array}$ & $F(4,70)$ & $p$ & $\eta^{2}$ \\
\hline Fluid reasoning & $12.53(2.70)$ & $12.67(3.18)$ & $12.40(2.85)$ & $14.13(2.20)$ & $12.73(2.58)$ & 1.01 & .41 & .05 \\
\hline Speed of processing & $21.80(5.00)$ & $21.33(7.04)$ & $22.87(7.03)$ & $28.53(9.65)$ & $27.20(8.59)$ & 1.97 & .11 & .10 \\
\hline Auditory attention & $25.46(3.24)$ & $25.87(3.58)$ & $24.27(3.01)$ & $26.80(3.28)$ & $25.73(2.40)$ & 1.27 & .29 & .07 \\
\hline EOWVPT & $65.93(10.80)$ & $47.93(10.81)$ & $53.27(10.95)$ & $66.47(12.30)$ & $81.97(9.47)$ & 20.31 & $<.001$ & .54 \\
\hline Formulated Sentences & $11.27(3.17)$ & $6.07(5.34)$ & $6.07(4.82)$ & $10.87(2.56)$ & $19.20(4.51)$ & 23.32 & $<.001$ & .57 \\
\hline Sentence Structures & $19.40(3.56)$ & $14.40(2.87)$ & $15.40(2.85)$ & $19.27(2.94)$ & $23.07(2.15)$ & 21.45 & $<.001$ & .55 \\
\hline Word Structure & $16.47(3.72)$ & $9.47(2.85)$ & $12.67(3.42)$ & $17.53(5.41)$ & $23.07(3.79)$ & 25.77 & $<.001$ & .60 \\
\hline Phonological Awareness & $32.27(19.11)$ & $17.40(10.78)$ & $18.27(7.12)$ & $47.60(16.93)$ & $50.07(10.22)$ & 19.61 & $<.001$ & .53 \\
\hline Recalling Sentences & $18.87(9.60)$ & $6.27(6.11)$ & $8.40(6.33)$ & $19.47(12.12)$ & $31.80(10.61)$ & 18.25 & $<.001$ & .51 \\
\hline
\end{tabular}

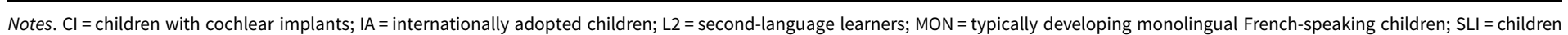
with specific language impairment. Fluid reasoning and speed of processing were assessed using the Matrices and Coding subtest of the Wechsler non-verbal IQ test, respectively. Auditory attention was assessed using the NEPSY. 
Table 4. Results of the Tukey HSD Post-Hoc Tests

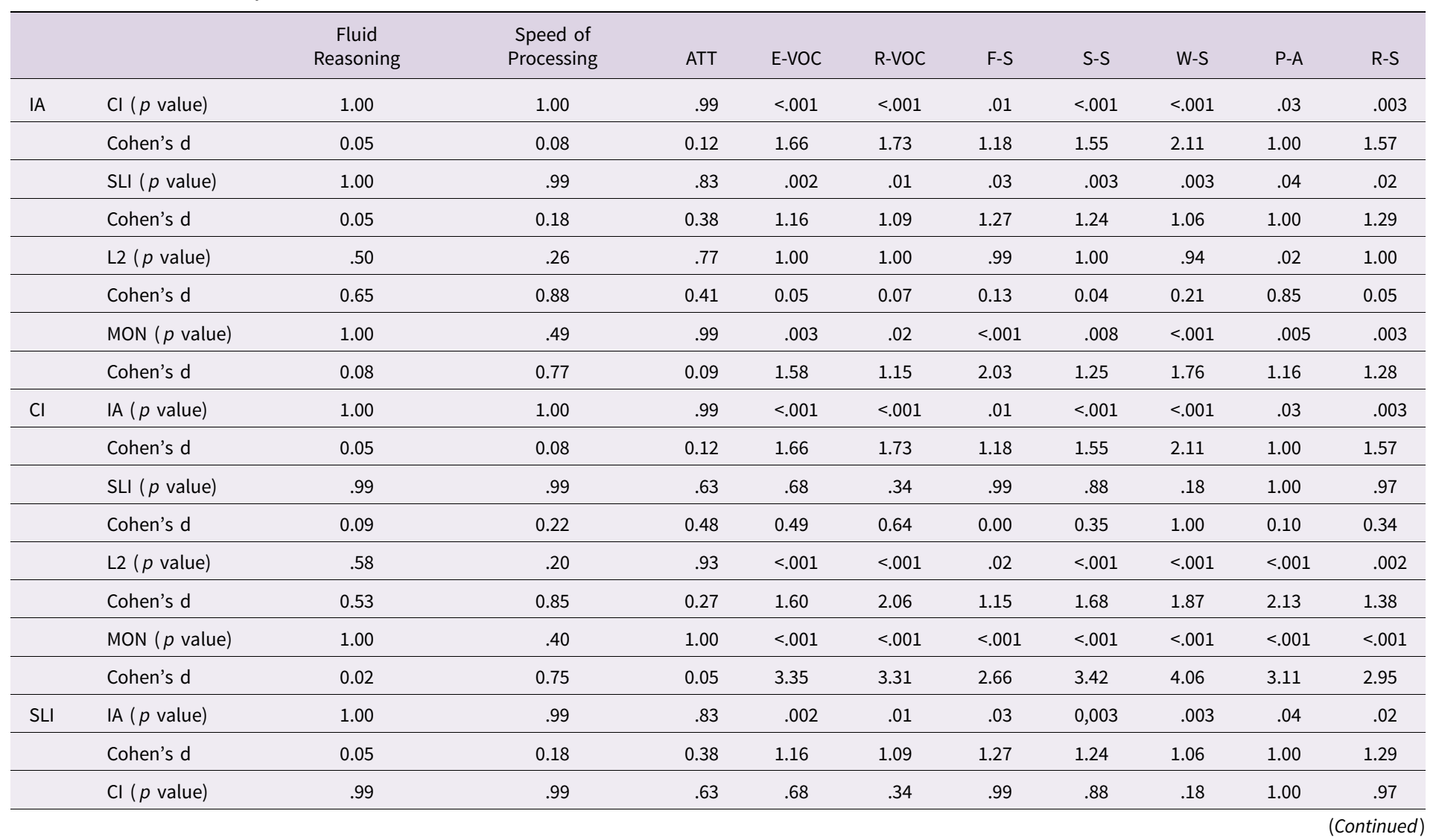




\begin{tabular}{|c|c|c|c|c|c|c|c|c|c|c|c|}
\hline & & $\begin{array}{c}\text { Fluid } \\
\text { Reasoning }\end{array}$ & $\begin{array}{l}\text { Speed of } \\
\text { Processing }\end{array}$ & ATT & E-VOC & R-VOC & F-S & S-S & W-S & P-A & R-S \\
\hline & Cohen's d & 0.09 & 0.22 & 0.48 & 0.49 & 0.64 & 0.00 & 0.35 & 1.00 & 0.10 & 0.34 \\
\hline & L2 ( $p$ value) & .41 & .44 & .19 & .01 & .006 & .05 & .005 & .01 & $<.001$ & .01 \\
\hline & Cohen's d & 0.68 & 0.67 & 0.80 & 1.14 & 2.50 & 2.66 & 1.34 & 1.07 & 2.26 & 1.15 \\
\hline & MON ( $p$ value) & .99 & .69 & .70 & $<.001$ & $<.001$ & $<.001$ & $<.001$ & $<.001$ & $<.001$ & $<.001$ \\
\hline & Cohen's d & 0.12 & 0.55 & 0.54 & 2.80 & 2.50 & 2.81 & 3.04 & 2.88 & 3.61 & 2.68 \\
\hline \multirow[t]{8}{*}{ L2 } & IA ( $p$ value) & .50 & .26 & .77 & 1.00 & 1.00 & .99 & 1.00 & .94 & .02 & 1.00 \\
\hline & Cohen's d & 0.65 & 0.88 & 0.41 & 0.05 & 0.07 & 0.13 & 0.04 & 0.21 & 0.85 & 0.05 \\
\hline & $\mathrm{Cl}$ ( $p$ value) & .58 & .20 & .93 & $<.001$ & $<.001$ & .02 & $<.001$ & $<.001$ & $<.001$ & .002 \\
\hline & Cohen's d & 0.53 & 0.85 & 0.27 & 1.60 & 2.06 & 1.15 & 1.68 & 1.87 & 2.13 & 1.38 \\
\hline & SLI ( $p$ value) & .41 & .44 & .19 & .01 & .006 & .05 & .005 & .01 & $<.001$ & .01 \\
\hline & Cohen's d & 0.68 & 0.67 & 0.80 & 1.14 & 2.50 & 2.66 & 1.34 & 1.07 & 2.26 & 1.15 \\
\hline & MON ( $p$ value) & .62 & .99 & .88 & .005 & .03 & $<.001$ & .006 & .002 & .98 & .004 \\
\hline & Cohen's d & 0.58 & 0.15 & 0.37 & 1.41 & 1.30 & 2.27 & 1.48 & 1.19 & .20 & 1.08 \\
\hline
\end{tabular}

Notes. ATT = auditory attention; $\mathrm{Cl}=$ children with cochlear implants; $\mathrm{MON}=$ typically developing monolingual French-speaking children; E-VOC = expressive vocabulary; F-S= Formulated

Sentences; IA = internationally adopted children; L2 = second language learners; P-A = Phonological Awareness; R-S = Recalling Sentences; R-VOC = receptive vocabulary; S-S = Sentence Structures; $\mathrm{SLI}=$ children with specific language impairment; $\mathrm{W}-\mathrm{S}=$ Word Structure. 
Table 5. Average Scores of the Groups Relative to Test Norms

\begin{tabular}{|c|c|c|c|c|c|c|c|}
\hline \multirow[b]{2}{*}{ Measures } & \multicolumn{2}{|c|}{ Norms } & \multirow{2}{*}{$\begin{array}{c}\mathrm{IA} \\
M(S D)\end{array}$} & \multirow{2}{*}{$\begin{array}{c}\mathrm{Cl} \\
M(S D)\end{array}$} & \multirow{2}{*}{$\begin{array}{c}\mathrm{SLI} \\
M(S D)\end{array}$} & \multirow{2}{*}{$\begin{array}{c}\mathrm{L} 2 \\
M(S D)\end{array}$} & \multirow{2}{*}{$\begin{array}{l}\text { MON } \\
M(S D)\end{array}$} \\
\hline & $M$ & {$[-1 S D,+1 S D]$} & & & & & \\
\hline Fluid reasoning & 50 & $40-60$ & $48.13(10.59)$ & $47.87(10.80)$ & $46.53(9.77)$ & $52.33(9.32)$ & $47.20(10.05)$ \\
\hline Speed of processing & 50 & $40-60$ & $51.80(7.32)$ & $48.86(7.80)$ & $50.07(9.57)$ & $54.73(6.90)$ & $53.20(6.90)$ \\
\hline Auditory attention & 10 & $7-13$ & $11.47(2.10)$ & $11.13(2.45)$ & $10.40(2.90)$ & $12.27(2.02)$ & $11.07(1.94)$ \\
\hline EOWVPT & 100 & $85-115$ & $103.87(12.59)$ & $82.00(12.47)$ & $88.47(11.81)$ & $103.13(16.67)$ & $119.47(15.34)$ \\
\hline EVIP & 100 & $85-115$ & $121.20(16.82)$ & $92.67(14.37)$ & $102.33(14.47)$ & $120.80(13.24)$ & $134.13(10.74)$ \\
\hline Formulated Sentences & 10 & $7-13$ & $7.20(1.47)$ & $5.40(2.26)$ & $5.93(2.19)$ & $7.13(1.51)$ & $10.33(1.84)$ \\
\hline Sentence Structures & 10 & $7-13$ & $9.33(3.06)$ & $5.13(2.83)$ & $6.47(2.39)$ & $8.87(2.29)$ & $12.73(2.99)$ \\
\hline Word Structure & 10 & $7-13$ & $8.26(2.25)$ & $4.27(1.83)$ & $6.67(2.29)$ & $8.87(3.29)$ & $12.00(2.80)$ \\
\hline Phonological Awareness & 10 & $7-13$ & $9.10(3.24)$ & $5.40(2.64)$ & $5.80(2.83)$ & $11.47(2.53)$ & $11.67(2.23)$ \\
\hline Recalling Sentences & 10 & $7-13$ & $4.87(2.72)$ & $1.93(1.28)$ & $2.73(1.49)$ & $5.20(3.00)$ & $8.27(2.91)$ \\
\hline
\end{tabular}

Notes $\mathrm{Cl}=$ children with cochlear implants; EOWPVT = Expressive One Word Picture Vocabulary Test; EVIP = Échelle de Vocabulaire en Images Peabody; IA = internationally adopted children; $\mathrm{L} 2=$ second-language learners; MON = typically developing monolingual French-speaking children; SLI = children with specific language impairment. The standard scores for fluid reasoning and speed of processing are expressed in T scores. 
particularly high-performing group insofar as they were from relatively high SES families and were free of any risk factor for language development. In contrast, the children with CIs and with SLI performed below the norms on all measures, except on measures of expressive and receptive vocabulary. The latter results can probably be explained, in part at least, by the use of English norms for the EOWPVT and by the fact that the norms of the EVIP are known to overestimate children's receptive vocabulary abilities (Simard, Fortier, \& Foucambert, 2011).

\section{Distribution of the scores in comparison to the MON children}

In order to better understand the children's results, the number of children in the IA, CI, and SLI groups who scored above and below the average of the MON children in terms of standard deviations was calculated for each language test (see Table 6). The group of L2 learners was included for comparison purposes. These analyses indicate that children's scores were substantially lower than those of the MON group, and also that a large number of children scored more than $2 S D$ s below the mean of the MON children. Again, it is important to keep in mind that the MON comparison group was a particularly high-performing group.

\section{Distribution of the scores in comparison to the $L 2$ learners}

Similar analyses were done to compare the IA children and the children with CIs to the L2 group, and thereby to compare all groups who experienced delayed onset of exposure to French. Interestingly, the performance of the IA children and the children with CIs was more comparable to the L2 learners than to the MON children, reinforcing the idea that L2 learners could be a better comparison group for IA children and children with CIs than monolingual children (see Table 7).

\section{Discussion}

To begin, we did not find significant differences between the groups with respect to general non-verbal cognitive ability, auditory attention, speed of processing, or socio-emotional adjustment. Of specific note, we did not find that the children with SLI exhibited speed of processing difficulties. On the one hand, this is consistent with the results of previous studies showing that not all children with SLI experience these difficulties (Miller, Kail, Leonard, \& Tomblin, 2001) but, on the other hand, the lack of auditory attention deficits in this group is not in line with studies reporting that children with SLI often exhibit auditory attention problems (Victorino \& Schwartz, 2015). Research has found that speech therapy and cognitive training often lead to significant improvements in auditory attention in children with SLI (Kapa \& Plante, 2015), a possibility that may explain the present results.

In terms of language results, we found, as expected, that the children with SLI and those with CIs scored significantly lower than the MON and L2 children whereas, in contrast, the IA children did not differ significantly from the L2 learners but did score significantly lower than the MON group. The IA children, in turn, performed significantly better than the children with SLI or with CIs. Neither the IA or L2 group or the SLI and CI groups differed significantly from one another - except for phonological awareness where the IA children performed significantly lower than the L2 learners. 
Table 6. Performance of the IA, Cl, SLI, and L2 Children in Comparison to the MON Children (\%; $\mathrm{n}$ )

\begin{tabular}{|c|c|c|c|c|c|c|}
\hline & {$[-2 S D]$} & {$[-2 S D ;-1 S D]$} & {$[-1 S D ; 0]$} & {$[0 ;+1 S D]$} & {$[+1 S D ;+2 S D]$} & {$[+2 S D]$} \\
\hline \multicolumn{7}{|c|}{ EOWPVT } \\
\hline IA & $(40 ; 6)$ & $(33 ; 5)$ & $(13 ; 2)$ & $(13 ; 2)$ & & \\
\hline L2 & $(47 ; 7)$ & $(13 ; 2)$ & $(27 ; 4)$ & $(13 ; 2)$ & & \\
\hline $\mathrm{Cl}$ & $(87 ; 13)$ & $(13 ; 2)$ & & & & \\
\hline SLI & $(80 ; 12)$ & $(20 ; 3)$ & & & & \\
\hline \multicolumn{7}{|l|}{ EVIP } \\
\hline IA & $(33 ; 5)$ & $(20 ; 3)$ & $(27 ; 4)$ & $(20 ; 3)$ & & \\
\hline L2 & $(20 ; 3)$ & $(40 ; 6)$ & $(33 ; 5)$ & $(7 ; 1)$ & & \\
\hline $\mathrm{Cl}$ & $(93 ; 14)$ & & $(7 ; 1)$ & & & \\
\hline SLI & $(67 ; 10)$ & $(33 ; 5)$ & & & & \\
\hline \multicolumn{7}{|c|}{ Formulated Sentences } \\
\hline IA & $(47 ; 7)$ & $(47 ; 7)$ & $(7 ; 1)$ & & & \\
\hline L2 & $(53 ; 8)$ & $(33 ; 5)$ & $(13 ; 2)$ & & & \\
\hline $\mathrm{Cl}$ & $(73 ; 11)$ & $(20 ; 3)$ & $(7 ; 1)$ & & & \\
\hline SLI & $(87 ; 13)$ & & $(13 ; 2)$ & & & \\
\hline \multicolumn{7}{|c|}{ Sentence Structures } \\
\hline IA & $(33 ; 5)$ & $(7 ; 1)$ & $(60 ; 9)$ & & & \\
\hline L2 & $(47 ; 7)$ & $(13 ; 2)$ & $(33 ; 5)$ & $(7 ; 1)$ & & \\
\hline $\mathrm{Cl}$ & $(100 ; 15)$ & & & & & \\
\hline SLI & $(93 ; 14)$ & $(7 ; 1)$ & & & & \\
\hline \multicolumn{7}{|c|}{ Word Structure } \\
\hline IA & $(47 ; 7)$ & $(27 ; 4)$ & $(27 ; 4)$ & & & \\
\hline L2 & $(33 ; 5)$ & $(40 ; 6)$ & $(20 ; 3)$ & $(7 ; 1)$ & & \\
\hline $\mathrm{Cl}$ & $(100 ; 15)$ & & & & & \\
\hline SLI & $(93 ; 14)$ & $(7 ; 1)$ & & & & \\
\hline \multicolumn{7}{|c|}{ Phonological Awareness } \\
\hline IA & $(53 ; 8)$ & $(20 ; 3)$ & $(7 ; 1)$ & & & $(20 ; 3)$ \\
\hline L2 & $(20 ; 3)$ & $(13 ; 2)$ & $(20 ; 3)$ & $(20 ; 3)$ & $(20 ; 3)$ & $(7 ; 1)$ \\
\hline $\mathrm{Cl}$ & $(80 ; 12)$ & $(13 ; 2)$ & $(7 ; 1)$ & & & \\
\hline SLI & $(93 ; 14)$ & $(7 ; 1)$ & & & & \\
\hline \multicolumn{7}{|c|}{ Recalling Sentences } \\
\hline IA & $(13 ; 2)$ & $(47 ; 7)$ & $(27 ; 4)$ & $(13 ; 2)$ & & \\
\hline L2 & $(40 ; 6)$ & $(13 ; 2)$ & $(27 ; 4)$ & $(20 ; 3)$ & & \\
\hline
\end{tabular}


Table 6. (Continued.)

\begin{tabular}{ccccccc}
\hline & {$[-2 S D]$} & {$[-2 S D ;-1 S D]$} & {$[-1 S D ; 0]$} & {$[0 ;+1 S D]$} & {$[+1 S D ;+2 S D]$} & {$[+2 S D]$} \\
\hline $\mathrm{Cl}$ & $(87 ; 13)$ & $(13 ; 2)$ & & & \\
\hline $\mathrm{SLI}$ & $(67 ; 10)$ & $(27 ; 4)$ & $(7 ; 1)$ & & \\
\hline
\end{tabular}

Notes. $\mathrm{Cl}=$ children with cochlear implants; EOWPVT = Expressive One Word Picture Vocabulary Test; EVIP=Échelle de Vocabulaire en Images Peabody; IA = internationally adopted children; L2 = second-language learners; MON = typically developing monolingual French-speaking children; $\mathrm{SLI}=$ children with specific language impairment.

In contrast to the overall pattern explained above, the IA group scored significantly lower than the L2 learners on phonological awareness. While both IA and L2 groups experienced a similar delay in exposure to their second language, the L2 learners might have had an advantage on phonological awareness due to their ongoing exposure to the birth language. There is evidence that L2 learners exhibit cognitive advantages, including in phonological awareness (Delcenserie \& Genesee, 2017). However, this raises the question of why the L2 group in the present study did not perform significantly better than the MON children on the test of phonological awareness.

Closer analyses of the CI, IA, and SLI groups' results indicated that their performance was well below that of the MON children. Although some children performed within one $S D$ of the performance of the MON children, a substantial percentage of children in each of these groups performed more than 2 SDs below the mean of the monolingual group on all language measures. It is also interesting to note that the performance of the IA children and the children with CIs was more comparable to the L2 group than to the MON children, thus suggesting that L2 learners could be a better comparison group for children who experience different types of delayed language exposure. Interpretation of these results should take into consideration that the MON children were from above average high SES families, and thus provide a very high point of comparison.

Although studies have found that the early language abilities of at-risk children, including late-talking children, predict their later language outcomes (e.g., Fernald \& Marchman, 2012), the present study is, to our knowledge, the first to show that risk factors for language acquisition that start early in life have differential effects on children's language development. That is to say, the magnitude of learners' vulnerabilities depends on the nature of their risk factors. More specifically, early risk associated with the absence of, or limited ability to process, early language input from birth are likely to have more consequential effects on language development, at least in the short term, than experiences that do not impede or interfere with access to very early input. In particular, the addition of a new language early in life following early exposure to the birth language, as in the case of international adoption or L2 learning, is likely to result in less significant effects. Taken together, these results suggest that, although delay is an important risk factor, delay with limited input or limited ability to process early input is more consequential than delay with normal input. These results reinforce others' findings that experiences during the first year of life are critical for the acquisition of language (e.g., Pierce et al., 2017; Werker \& Tees, 1999, 2002). In short, the first year of life appears to be particularly critical for laying the foundations and future development of language, since the groups in the present study with the most restricted input from birth had 
Table 7. Performance of the $\mathrm{IA}$ and $\mathrm{Cl}$ Children in comparison to the $\mathrm{L} 2$ Children $(\%, n)$

\begin{tabular}{|c|c|c|c|c|c|c|}
\hline & {$[-2 S D]$} & {$[-2 S D ;-1 S D]$} & {$[-1 S D ; 0]$} & {$[0 ;+1 S D]$} & {$[+1 S D ;+2 S D]$} & {$[+2 S D]$} \\
\hline \multicolumn{7}{|c|}{ EOWPVT } \\
\hline $\mathrm{IA}$ & & $(7 ; 1)$ & $(47 ; 7)$ & $(27 ; 4)$ & $(20 ; 3)$ & \\
\hline $\mathrm{Cl}$ & $(20 ; 3)$ & $(53 ; 8)$ & $(27 ; 4)$ & & & \\
\hline \multicolumn{7}{|l|}{ EVIP } \\
\hline $\mathrm{IA}$ & $(7 ; 1)$ & $(20 ; 3)$ & $(20 ; 3)$ & $(33 ; 5)$ & $(20 ; 3)$ & \\
\hline $\mathrm{Cl}$ & $(60 ; 9)$ & $(33 ; 5)$ & & $(7 ; 1)$ & & \\
\hline \multicolumn{7}{|c|}{ Formulated Sentences } \\
\hline IA & & $(13 ; 2)$ & $(33 ; 5)$ & $(27 ; 4)$ & $(20 ; 3)$ & $(7 ; 1)$ \\
\hline $\mathrm{Cl}$ & $(53 ; 8)$ & $(13 ; 2)$ & $(7 ; 1)$ & $(13 ; 2)$ & $(7 ; 1)$ & $(7 ; 1)$ \\
\hline \multicolumn{7}{|c|}{ Sentence Structures } \\
\hline IA & $(13 ; 2)$ & & $(20 ; 3)$ & $(60 ; 9)$ & $(7 ; 1)$ & \\
\hline $\mathrm{Cl}$ & $(40 ; 6)$ & $(20 ; 3)$ & $(40 ; 6)$ & & & \\
\hline \multicolumn{7}{|c|}{ Word Structure } \\
\hline IA & & $(7 ; 1)$ & $(53 ; 8)$ & $(40 ; 6)$ & & \\
\hline $\mathrm{Cl}$ & $(13 ; 2)$ & $(67 ; 10)$ & $(20 ; 3)$ & & & \\
\hline \multicolumn{7}{|c|}{ Phonological Awareness } \\
\hline IA & $(20 ; 3)$ & $(33 ; 5)$ & $(27 ; 4)$ & $(20 ; 3)$ & & \\
\hline $\mathrm{Cl}$ & $(53 ; 8)$ & $(27 ; 4)$ & $(20 ; 3)$ & & & \\
\hline \multicolumn{7}{|c|}{ Recalling Sentences } \\
\hline IA & & & $(60 ; 9)$ & $(27 ; 4)$ & $(13 ; 2)$ & \\
\hline $\mathrm{Cl}$ & $(67 ; 10)$ & & $(33 ; 5)$ & & & \\
\hline
\end{tabular}

Notes. $\mathrm{Cl}$ = children with cochlear implants; EOWPVT = Expressive One Word Picture Vocabulary Test; EVIP = Échelle de Vocabulaire en Images Peabody; IA = internationally adopted children; L2 = second-language learners; MON = typically developing monolingual French-speaking children; SLI = children with specific language impairment.

the lowest scores. At the same time, these findings suggest that even less significant changes in early in life, such as those experienced by IA and L2 learners, may have consequences for language learning.

The present results also suggest that the at-risk groups experienced the same domains of vulnerability with respect to language development insofar as all groups of interest exhibited weaknesses in all domains of testing. Of particular note, and in corroboration of the fMRI results reported by Pierce et al. (2014b, 2015), the IA and L2 learner groups demonstrated similar overall patterns of development despite differences in retention of the birth language in these two groups. These results also support the claims of Rice (2016), who suggested that the language learning outcomes of young children with CI reveal unexplained individual differences and language growth trajectories that are similar to those of children with SLI. Multi-group comparisons are thus particularly interesting in showing what is robust and what is vulnerable in language acquisition under different conditions of language acquisition. 
To conclude, the present study has limitations that should be highlighted for future studies. First, the present study is a one-time 'snapshot' of these groups' language abilities, and thus longitudinal studies of long-term language development are clearly called for. The children in the present study were relatively young, and those with delay had relatively limited exposure to language at the time of testing. It is therefore possible that, with age and more language exposure, their profiles will change and that some domains of language will show more growth than others. In a related vein, the outcomes exhibited in this short-term study do not mean that children in these groups cannot acquire advanced levels of language proficiency.

Second, although statistically significant differences were found between these broadly defined groups of learners, more specific and detailed analyses of withingroup variation in early language experiences are called for to form a complete picture of the effects of varied aspects of early experience. In some cases, examining more specific aspects of early language experience may be difficult because parents are often unable to provide or recall details of their child's early language experiences, and in some cases detailed information about early experiences may not be available (e.g., IA children).

Third, the present study employed standardized measures of general language ability. That all three at-risk groups had the same profile of vulnerability might mean that our battery of tests was not specific or sensitive enough to reveal differential vulnerabilities. More detailed and in-depth testing is called for in future studies to examine this possibility. In fact, additional data were collected using both elicitation tasks and naturalistic language samples with the same participants, and this will allow us to explore variation among these at-risk groups in more depth and detail.

Acknowledgements. The authors would like to thank Lara Pierce and Gary Morgan for their helpful comments. We would also like to thank Lélia Farout, Deborah Angelus, and Manon Rivest for their help with recruitment, as well as Kristina Maiorino and Cynthia Ayvazian for their help with testing. This research was funded by the Centre for Research on Brain, Language, and Music (CRBLM), the Social Sciences and Humanities Research Council (SSHRC), and the Fonds the Recherche du Québec - Société et Culture (FQRSC).

\section{References}

Abrahamsson, N., \& Hyltenstam, K. (2009). Age of onset and nativelikeness in a second language: listener perception versus linguistic scrutiny. Language Learning 59, 249-306.

Achenbach, T. M., \& Rescorla, L. (2000). Manual for ASEBA preschool forms and profiles. Burlington, VT: University of Vermont, Research Center for Children, Youth, and Families.

Alloway, T. P., \& Gathercole, S. E. (2005). The role of sentence recall in reading and language skills of children with learning difficulties. Learning and Individual Differences 15, 271-82.

Bishop, D. V. M. (2006). Developmental cognitive genetics: how psychology can inform genetics and vice versa. Quarterly Journal of Experimental Psychology 59, 1153-68.

Bouton, S., Colé, P., Serniclaes, W., Duncan, L., \& Giraud, A.-L. (2015). Atypical phonological processing impairs word recognition in children with cochlear implants. Language, Cognition, and Neuroscience 30, 684-99.

Brownell, R. (2000). Manual for the Expressive One-Word Picture Vocabulary Test (EOWPVT). Novato, CA: Academic Therapy Publications.

Caselli, M. C., Rinaldi, P., Varuzza, C., Giulani, A., \& Burdo, S. (2012). Cochlear implant in the second year of life: lexical and grammatical outcomes. Journal of Speech, Language, and Hearing Research 55, 382-94.

Chilosi, A. M., Comparini, A., Scusa, M. F., Orazini, L., Forli, F., Cipriani, P., \& Berrettini, S. (2013). A longitudinal study of lexical and grammar development in deaf Italian children provided with early cochlear implantation. Ear and Hearing 34, 28-37. 
Colantoni, L., \& Steele, J. (2006). Native-like attainment in the L2 acquisition of Spanish stop-liquid clusters. In C. A. Klee \& T. L. Face (Eds.), Selected proceedings of the 7th conference on the acquisition of Spanish and Portuguese as first and second languages (pp. 59-73). Somerville, MA: Cascadilla Proceedings Project.

Conti-Ramsden, G., Crutchley, A., \& Botting, N. (1997). The extent to which psychometric tests differentiate subgroups of children with specific language impairment. Journal of Speech, Language, and Hearing Research 40, 765-77.

Conti-Ramsden, G., \& Durkin, K. (2011). Specific language impairment. In D. Skuse, H. Bruce, L. Dowdney, \& D. Mrazek (Eds.), Child psychology and psychiatry: frameworks for practice (pp. 180-5). Chichester: John Wiley \& Sons.

Delcenserie, A., \& Genesee, F. (2014). Language and memory abilities of internationally-adopted children from China. Journal of Child Language 41, 1195-223.

Delcenserie, A., \& Genesee, F. (2017). The effects of age of acquisition and bilingualism on verbal working memory. International Journal of Bilingualism 21, 600-16.

Delcenserie, A., Genesee, F., \& Gauthier, K. (2013). Language abilities of internationally-adopted children from China: Evidence for early age effects? Applied Psycholinguistics 34, 541-68.

Dettman, D. J., Pinder, D., Briggs, R. J., Dowell, R. C., \& Leigh, J. R. (2007). Communication development in children who receive the cochlear implant younger than 12 months: risks versus benefits. Ear and Hearing 28, 11-18.

Dunn, L. M., Theriault-Whalen, C. M., \& Dunn, L. M. (1993). Manual for the échelle de vocabulaire en images Peabody. Toronto, ON: Psycan Corporation.

Fernald, A., \& Marchman, V. A. (2012). Individual differences in lexical processing at 18 months predict vocabulary growth in typically-developing and late-talking toddlers. Child Development 83, 203-22.

Geers, A. E., Brenner, C., \& Davidson, L. (2003). Factors associated with developmental speech perception skills in children implanted by age five. Ear and Hearing 24, 24-35.

Hoff, E. (2006). How social contexts support and shape language development. Developmental Review 26, $55-88$.

Hyltenstam, K. (1992). Non-native features of near-native speakers: on the ultimate attainment of childhood L2 learners. In R. J. Harris (Ed.), Cognitive processing in bilinguals (pp. 351-68). Amsterdam: Elsevier Science.

Hyltenstam, K., Bylund, E., Abrahamsson, N., \& Park, H. (2009). Dominant language replacement: the case of international adoptees. Bilingualism: Language and Cognition 12, 121-40.

Jia, G. (2003). The acquisition of the English plural morpheme by native Mandarin Chinese-speaking children. Journal of Speech, Language, and Hearing Research 46, 1297-311.

Kapa, L. L., \& Plante, E. (2015). Executive function in SLI: recent advances and future directions. Current Developmental Disorders Reports 2, 245-52.

Klem, M., Melby-Lervåg, M., Hagtvet, B., Solveig-Alma, H. L., Gustafsson, J.-E., \& Hulme, C. (2015). Sentence repetition is a measure of children's language skills rather than working memory limitations. Developmental Science 18, 146-54.

Korkman, M., Kirk, U., \& Kemp, S. (2007). NEPSY- Second Edition (NEPSY-II). San Antonio, TX: Harcourt Assessment.

Kronenberger, W. G., Pisoni, D. B., Harris, M. S., Hoen, H. M., Xu, H., \& Miyamoto, R. T. (2013). Profiles of verbal working memory growth predict speech and language development in children with cochlear implants. Journal of Speech, Language, and Hearing Research 56, 805-25.

Kronenberger, W. G., Pisoni, D. B., Henning, S. C., Colson, B. G., \& Hazzard, L. M. (2011). Working memory training for children with cochlear implants: a pilot study. Journal of Speech, Language, and Hearing Research 54, 1182-96.

Kuhl, P. K., Ramírez, R. R., Bosseler, A., Lin, J.-F. L., \& Imada, T. (2014). Infants' brain responses to speech suggest analysis by synthesis. Proceedings of the National Academy of Sciences of the United States of America 111, 11238-45.

Leonard, L. B. (2014). Children with specific language impairment, 2nd ed. Cambridge, MA: MIT Press.

Lum, J. A., Conti-Ramsden, G., Page, D., \& Ullman, M. T. (2012). Working, declarative, and procedural memory in specific language impairment. Cortex 48, 1138-54. 
Mayberry, R. I. (2007). When timing is everything: age of first-language acquisition effects on second-language learning. Applied Psycholinguistics 28, 537-49.

Meisel, J. M. (2004). The bilingual child. In T. K. Bhatia \& W. C. Ritchie (Eds.), The handbook of bilingualism (pp. 91-113). Oxford: Blackwell.

Miller, C. A., Kail, R., Leonard, L. B., \& Tomblin, J. B. (2001). Speed of processing in children with specific language impairment. Journal of Speech, Language, and Hearing Research 44, 416-33.

Nicholas, J. G., \& Geers, A. E. (2007). Will they catch up? The role of age at cochlear implantation in the spoken language development of children with severe to profound hearing loss. Journal of Speech, Language, and Hearing Research 50, 1048-62.

Nicholas, J. G., \& Geers, A. E. (2013). Spoken language benefits of extending cochlear implant candidacy below 12 months of age. Otology \& Neurotology 34, 532-8.

Nicoladis, E., \& Marchak, K. (2011). Le carte blanc or la carte blanche? Bilingual children's acquisition of French adjective agreement. Language Learning 61, 734-58.

Nicoladis, E., Palmer, A., \& Marentette, P. (2007). The role of type and token frequency in using past tense morphemes correctly. Developmental Science 10, 237-54.

Niparko, J. K., Tobey, E. A., Thal, D. J., Eisenberg, L. S., Wang, N. Y., Quittner, A. L., ... CDaCI Investigative Team (2010). Spoken language development in children following cochlear implantation. Journal of the American Medical Association 303, 1498-506.

Nittrouer, S., Lowenstein, J. H., \& Holloman, C. (2016). Early predictors of phonological and morphosyntactic skills in second graders with cochlear implants. Research in Developmental Disabilities 55, 143-60.

O’Donoghue, G. M., Nikolopoulos, T. P., \& Archbold, S. M. (2000). Determinants of speech perception in children after cochlear implantation. Lancet 356, 466-8.

Paradis, J. (2006). Second language acquisition in childhood. In J. Paradis, F. Genesee, \& M. Crago (Eds.), Dual language development \& disorders (pp. 387-406). Baltimore, MD: Brookes.

Paradis, J. (2011). Individual differences in child English second language acquisition. Linguistic Approaches to Bilingualism 1, 213-37.

Paradis, J., \& Crago, M. (2000). Tense and temporality: similarities and differences between language-impaired and second-language children. Journal of Speech, Language, and Hearing Research 43, 834-48.

Pierce, L. J., Chen, J. K., Delcenserie, A., Genesee, F., \& Klein, D. (2015). Past experience shapes ongoing neural patterns for language. Nature Communications 6. Retrieved from <https://www.nature.com/ articles/ncomms10073>.

Pierce, L. J., Genesee, F., Delcenserie, A., \& Morgan, G. (2017). Variations in PWM: linking early language experiences and language learning outcomes. Applied Psycholinguistics 38, 1265-300.

Pierce, L. J., Genesee, F., Gauthier, K., \& DuBois, M. E. (2014a). Communication patterns between parents and children: comparing mothers and fathers in different learner contexts. Applied Psycholinguistics 36, 1223-46.

Pierce, L., Klein, D., Chen, J.-K., Delcenserie, A., \& Genesee, F. (2014b). Mapping the unconscious maintenance of a lost first language. Proceedings of the National Academy of Sciences 111, 17314-19.

Pomerleau, A, Malcuit, G., Chicoine, J.-F., Séguin, R., Belhumeur, C., Germain, P. ... Jéliu, G. (2005). Health status, cognitive and motor development of young children adopted from China, East Asia, and Russia across the first 6 months after adoption. International Journal of Behavioral Development 29, 445-57.

Rice, M. L. (2016). Specific language impairment, nonverbal IQ, attention-deficit/hyperactivity disorder, autism spectrum disorder, cochlear implants, bilingualism, and dialectal variants: defining the boundaries, clarifying clinical conditions, and sorting out causes. Journal of Speech, Language, and Hearing Research 59, 122-32.

Rice, J., Jackson, A., Mahoney, E. E., \& Tan, T. X. (2016). Pre-adoption stress, adversity, and later development in IA children. In F. Genesee \& A. Delcenserie (Eds.), Starting over: the language development of internationally-adopted children (pp. 95-124) (Trends in Language Acquisition Research series (TiLAR)). Amsterdam: John Benjamins Publishing.

Rutter, M. (2012). Resilience as a dynamic concept. Developmental Psychopathology 24, 335-44.

Scott, K., \& Roberts, J. (2016). Language development during the preschool years. In F. Genesee \& A. Delcenserie (Eds.), Starting over: the language development of internationally-adopted children (pp. 
65-94) (Trends in Language Acquisition Research series (TiLAR)). Amsterdam: John Benjamins Publishing.

Scott, K., Roberts, J., \& Krakow, R. (2008). Oral and written language development of children adoption from China. American Journal of Speech-Language Pathology 17, 150-60.

Semel, E., Wiig, E. H., \& Secord, W. A. (2009). Évaluation clinique des notions langagières fondamentales - Version pour francophones du Canada. Toronto: Psychological Corporation.

Semel, E., Wiig, E. H., Secord, W. A., \& Sabers, D. (1987). CELF-R: Clinical Evaluation of Language Fundamentals - Revised (technical manual). New York: Psychological Corporation.

Simard, D., Fortier, V., \& Foucambert, D. (2011). Measuring metasyntactic ability among heritage language children. Bilingualism: Language and Cognition 16, 19-31.

Szagun, G. (2004). Learning by ear: on the acquisition of case and gender marking by German-speaking children with normal hearing and with cochlear implants. Journal of Child Language 31, 1-30.

Thordardottir, E. (2011). The relationship between bilingual exposure and vocabulary development. International Journal of Bilingualism 15, 426-45.

Thordardottir, E. (2015). The relationship between bilingual exposure and morphosyntactic development. International Journal of Speech-Language Pathology 17, 97-114.

Thordardottir, E., \& Brandeker, M. (2013). The effect of bilingual exposure versus language impairment on nonword repetition and sentence imitation scores. Journal of Communication Disorders 46, 1-16.

Tomblin, J. B., Harrison, M., Ambrose, S. E., Walker, E. A., Oleson, J. J., \& Moeller, M. P. (2015). Language outcomes in young children with mild to severe hearing loss. Ear and Hearing 36, 76-91.

van der Lely, H. K. J. (1996). Specifically language impaired and normally developing children: verbal passive vs. adjectival passive sentence interpretation. Lingua 98, 243-72.

Victorino, K. R., \& Schwartz, R. G. (2015). Control of auditory attention in children with specific language impairment. Journal of Speech, Language, and Hearing Research 58, 1245-57.

Vlastarakos, P. V., Poikas, K., Papacharalampous, G., Exadaktylou, I., Mochloulis, G., \& Nikolopoulos, T. P. (2010). Cochlear implantation under the first year of age - the outcomes: a critical systematic review and meta-analysis. International Journal of Pediatric Otorhinolaryngology 74, $119-26$.

Vugs, B., Hendriks, M., Cuperus, J., \& Verhoeven, L. (2014). Interactions between working memory and language in young children with specific language impairment. Research in Developmental Disabilities $35,62-74$.

Wechsler, D., \& Naglieri, J. (2006). Wechsler non-verbal scale of ability. Toronto: Harcourt Assessment.

Werker, J. F., \& Tees, R. C. (1999). Influences on infant speech processing: toward a new synthesis. Annual Review of Psychology 50, 509-35.

Werker, J. F., \& Tees, R. C. (2002). Cross-language speech perception: evidence for perceptual reorganization during the first year of life. Infant Behavior \& Development 25, 121-33.

Cite this article: Delcenserie A, Genesee F, Trudeau N, Champoux F (2019). A multi-group approach to examining language development in at-risk learners. Journal of Child Language 46, 51-79. https://doi.org/ 10.1017/S030500091800034X 